\title{
Toll-Like Receptor 5 of Golden Pompano Trachinotus ovatus (Linnaeus 1758): Characterization, Promoter Activity and Functional Analysis
}

\author{
Ke-Cheng Zhu ${ }^{1,2,+} \mathbb{D}$, Meng Wu ${ }^{1,+}$, Dian-Chang Zhang ${ }^{1,2,3,4, *}$, Hua-Yang Guo ${ }^{1,2}$, Nan Zhang ${ }^{1,2}$, \\ Liang Guo ${ }^{1,2}$, Bao-Suo Liu ${ }^{1,2}$ and Shi-Gui Jiang ${ }^{1,2,4}$ \\ 1 Key Laboratory of South China Sea Fishery Resources Exploitation and Utilization, Ministry of Agriculture \\ and Rural Affairs, South China Sea Fisheries Research Institute, Chinese Academy of Fishery Sciences, \\ Guangzhou 510300, China; zkc537@163.com (K.-C.Z.); 13871270376@163.com (M.W.); \\ guohuayang198768@163.com (H.-Y.G.); 398730316@163.com (N.Z.); zsdxg1@163.com (L.G.); \\ liubaosuo343@163.com (B.-S.L.); jiangsg@21cn.com (S.-G.J.) \\ 2 Guangdong Provincial Engineer Technology Research Center of Marine Biological Seed Industry, \\ Guangzhou 510300, China \\ 3 Tropical Aquaculture Research and Development Center, South China Sea Fisheries Research Institute, \\ Chinese Academy of Fishery Sciences, Sanya 572018, China \\ 4 Sanya Tropical Fisheries Research Institute, Sanya 510300, China \\ * Correspondence: zhangdch@scsfri.ac.cn; Tel.: +86-020-8910-8316; Fax: +86-020-8902-2702 \\ + These authors contributed equally to this work.
}

Received: 6 July 2020; Accepted: 17 August 2020; Published: 18 August 2020

\begin{abstract}
Toll-like receptors (TLRs), as important pattern recognition receptors, represent a significant component of fish immune systems and play an important role in resisting the invasion of pathogenic microorganisms. The TLR5 subfamily contains two types of TLR5, the membrane form of TLR5 (TLR5M) and the soluble form of TLR5 (TLR5S), whose detailed functions have not been completely elucidated. In the present study, we first identified two genes, TLR5M (ToTLR5M) and TLR5S (ToTLR5S), from golden pompano (Trachinotus ovatus). The full-length ToTLR5M and ToTLR5S cDNA are $3644 \mathrm{bp}$ and $2329 \mathrm{bp}$, respectively, comprising an open reading frame (ORF) of $2673 \mathrm{bp}$, encoding 890 amino acids, and an ORF of $1935 \mathrm{bp}$, encoding 644 amino acids. Both the ToTLR5s possess representative TLR domains; however, only ToTLR5M has transmembrane and intracellular TIR domains. Moreover, the transcription of two ToTLR5s was significantly upregulated after stimulation by polyinosinic:polycytidylic acid (poly (I:C)), lipopolysaccharide (LPS), and flagellin in both immune-related tissues (liver, intestine, blood, kidney, and skin) and nonimmune-related tissue (muscle). Furthermore, the results of bioinformatic and promoter analysis show that the transcription factors GATA-1 (GATA Binding Protein 1), C/EBPalpha (CCAAT Enhancer Binding Protein Alpha), and ICSBP (Interferon (IFN) consensus sequence binding protein) may play a positive role in moderating the expression of two ToTLR5s. Overexpression of ToTLR5M and ToTLR5S notably increases $N F-\kappa B$ (nuclear factor kappa-B) activity. Additionally, the binding assay revealed that two rToTLR5s can bind specifically to bacteria and pathogen-associated molecular patterns (PAMPs) containing Vibrio harveyi, Vibrio anguillarum, Vibrio vulnificus, Escherichia coli, Photobacterium damselae, Staphylococcus aureus, Aeromonas hydrophila, LPS, poly(I:C), flagellin, and peptidoglycan (PGN). In conclusion, the present study may help to elucidate the function of ToTLR5M/S and clarify their possible roles in the fish immune response to bacterial infection.
\end{abstract}

Keywords: Trachinotus ovatus; promoter activity; Toll-like receptor 5; binding assay 


\section{Introduction}

Toll-like receptors (TLRs) play an important role in host defense in both invertebrates and vertebrates [1]. The TLR family, a key pathogen recognition receptor (PRR), primarily participates in the innate immune and acquired immune systems. In higher vertebrates, the TLR family is regarded as a pivotal mediator that activates innate immunity and develops antigen-specific acquired immunity against invading microorganisms and pathogens, such as peptidoglycan, lipoprotein, lipopolysaccharide (LPS), flagellin, and polyinosinic:polycytidylic acid (poly(I:C)) [2-4]. To date, as TLRs are type I transmembrane proteins, 13 types of TLRs have been reported in mammals $[5,6]$. According to cellular localization, TLRs are classified into two major subfamilies: the cell surface subfamily (TLRs 1, 2, 4, 5, 6, and 10) and the endolysosomal compartment subfamily (TLRs 3, 7, 8, and 9) [4]. TLRs include three typical domains: the extracellular, transmembrane, and intracellular domains [7]. The extracellular domain is composed of several $\mathrm{N}$-terminal leucine-rich repeats (LRRs) and is involved in recognition of pathogen-associated molecular patterns (PAMPs) [8]. Moreover, the intracellular domain possesses a representative Toll/IL-1 (Interleukin-1) receptor (TIR) domain that is analogous to the IL1R family intracellular domain [9] and plays a pivotal role in signal transduction.

As a TLR family member, TLR5 is a key PRR and can recognize PAMPs, such as the bacterial flagellum protein, by touching their flagellin [10-13]. TLR5 is reasonable for flagellin-mediated $N F-\kappa B$ activation by the MyD88-dependent pathway in the cellular membrane [14]. Two types of TLR5 are found in teleosts: the membrane form of TLR5 (TLR5M) and the soluble form of TLR5 (TLR5S) [15-18]. In other fish species, only TLR5M in Cirrhinus mrigala, Danio rerio, Ctenopharyngodon idelus, Oplegnathus fasciatus, Pangasianodon hypophthalmus, and Paralichthys olivaceus [13,19-23] or TLR5S in Onchorhynchus mykiss, Salmo salar, Ictalurus punctatus, Cynoglossus semilaevis, and Miichthys miiuy [16,24-27] have been isolated and reported. Furthermore, TLR5M is composed of the TIR domain transmembrane region and the LRR domain, but TLR5S has no TIR domain or transmembrane region by comparison. A recent study showed that TLR5M identified flagellin, and NF-KB was activated to induce some immune response genes and TLR5S [16]. TLR5S was induced to recognize flagellin in the fluid phase and later bound to TLR5M to amplify the signal cascade [17].

The golden pompano Trachinotus ovatus (Linnaeus 1758), Carangidae, Perciformes, is widely distributed in the Asia-Pacific region. This fish is popular because of its fast growth and high-quality flesh and is known as an important commercial fish in China $[28,29]$. However, in T. ovatus, a high death rate is attributed to viral and bacterial infections [30]. To characterize the host immune defense and host-pathogen relationships of TLR5 in T. ovatus (ToTLR5), we determined the role of ToTLR5 after stimulation with poly(I:C), LPS, and flagellin, and the genomic sequence, expression pattern, and transcriptional regulation of ToTLR5 were also determined. Our results suggest that ToTLR5 may play an important role as a PRR in the immune response to pathogen infections and may be involved in the NF-kB activation pathway.

\section{Results}

\subsection{Sequence Characterization of ToTLR5M and ToTLR5S}

The cDNA sequence of ToTLR5M is $3644 \mathrm{bp}$, including $612 \mathrm{bp}$ of the $5^{\prime}$ untranslated region (5'-UTR); a 2673 bp open reading frame (ORF) encoding a polypeptide of 890 amino acids (GenBank accession number: MT596697; Figure 1A); and a 359 bp 3'-UTR, with a predicted molecular weight of $96.31 \mathrm{kDa}$ and a theoretical isoelectric point of 5.94. The cDNA sequence of ToTLR5S is $2329 \mathrm{bp}$, including $156 \mathrm{bp}$ of the $5^{\prime}$ untranslated region (5'-UTR); a $1935 \mathrm{bp}$ ORF encoding a polypeptide of 644 amino acids (GenBank accession number: MT596698; Figure 1B); and a 238 bp 3'-UTR, with a predicted molecular weight of $72.21 \mathrm{kDa}$ and a theoretical isoelectric point of 8.84 . Moreover, the amino acid sequence of ToTLR5M contains typical TLR protein domains, eight LRR domains (65-528 aa), one LRR-CT domain (537-590 aa), one transmembrane domain (603-625 aa), and one intracellular TIR domain (654-801 aa) (Figures 1A and 2A). The amino acid sequence of ToTLR5S includes 1 LRR-NT 
domain (19-50 aa), 14 LRR domains (45-583 aa), and 1 LRR-CT domain (592-644 aa) (Figures 1B and 2A). Furthermore, in TLR5M, the result of amino acid sequence alignment of the TIR domain showed that this region contains three conserved functional boxes (Box1, Box2, and Box3) (Figure 2B). Additionally, comparison of the exon-intron organization of TLR5 shows that the genomic sequences of ToTLR5M and ToTLR5S include four exons, three introns, two exons, and one intron, respectively (Figure S1).

A

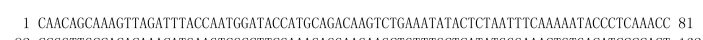
82 CCGGTTGCCACACAAACATGAAGTGGCCTTCGAAGGGGGAGGAGCTGTTTGCTCATATGGGAAACTGTGACATCCCCACT 162 243 TTGGTCCATGCAACAGAGGATCTACAGCAGGCAAGTGTCGGGGTCGCAGAGCAGAAGTGTATCAGTCGCAGTTTTCCAGAC 243 325 TTGCAGGGGGGTCCTGGGGGGCAGGAGCTGAGGCCAAACATGCCAACCATGAGAGCGGAGCCTTATTGTTCAAGCGGATGT 405

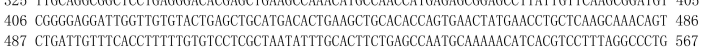
8 CTCATTTTTGACTCTCTCTGGCCTCGCTAATATTTGCACTTCTGAGCCAATGCAAAAACATCACGTCCTTTAGGCCCTG 567 $\begin{array}{rlllll}1 & \end{array}$ 649 ttacacctacaggtaaccacatgctacgcagcatgcactttatatggccttatagcttcttgcacctcacagcgctactac 729

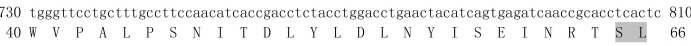
811 agagattatgtccatctgcagcaattagacctgggaatgcagagagtgcaacttgtcataaggaacaacgctttcctaagg 891 92 cagacaaaattgacacgtttggttctgggccagaatactggtcttcagctggagccaagggcatttgcaggactgtataat 972 121 tacaacacctctttctggat tattgcaatttgagagactccatactgacggaaagctatctgcagccccttttgtcctta 1057

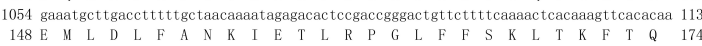
1135 ttaaacctcaaattgaataagact taaacgat tatgtgaaggggatcttgttggtttcagggggaaatacttcacactcctg 12 1216 aacttgcactccaacaagttaggtagaatgtatgaagaagattttgacaaggaaagttgtggtaaccetttcaaagggatg 129 1297 acttttaatgtccttgatttatcccttaatgatttcaatgtgatcacaataagacaatttttcaaagccatagaggggact 1377

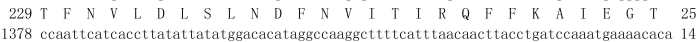
1378 ccaattcatcaccttatattatatggacacataggccaaggcttttcatttaacaact tacctgatccaaatgaaacaca 145
256 P I H H L I L Y G H I G Q G F S F N N L P D P N E N T 282

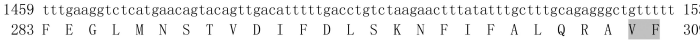

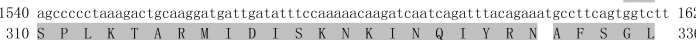
1621 caagggcatttaatgattctcaacctgtcatccaacctgctaggagagatatat tcacacacattcatcagtctcacagag 170 702 cttagggtgttggatttgtctcacaaccacattggtgcattgggacaccaagtcttcagtggtcttcccaaattacaaagt 178

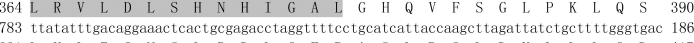
1864 aataagttgaaatcgctaagaggtattactaacttgggtggtaacagcatctatgtggacattacagacaacaggttaatg 1944

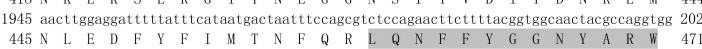
2026 tgtacactaaatgggat tat tacagtacctcataataatagtttgcaagtgctagatcttcatggcagttccctgcagata
472 C T L N G I I T V P H N N S L Q V L D L H G S S L Q I
2

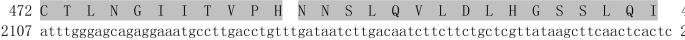

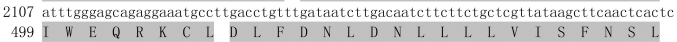
2188 acgaatctgecggaagggattttcagaggtctccactcgatcatagagatcgacctctcgtctaattccttgacctatctg 226

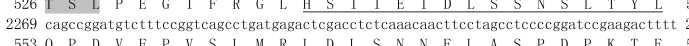

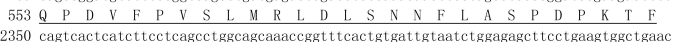

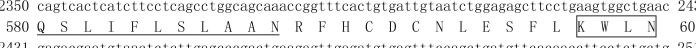
2431 gagacgatgtaactctcttgagcccgactgaagagttgagatgtgagtttccagctgatgttcacaaccttcctctgctg 251

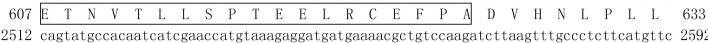
2512 cagtatgccacaatcatcgaaccatgtaagaggatgatgaaaacgctgtccaagatcttaagtttgccctcttcatgttc 2592
634 Q 2593 tctgccetcctcatcatcactgtcaccctcagcggcattgtttacgetcgtctccgagggcacatattcatcatctacaaa 2673

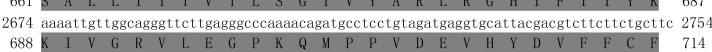

2755 a
715
$\mathrm{~N}$$$
\begin{array}{r}
2836 \\
742
\end{array}
$$$$
\begin{array}{r}
742 \\
769
\end{array}
$$

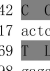

B

1 GTTTGTGCTGCACAATCACAGTAATGCCCACCACAAGTGACACAGACACTCACAGATAAAACCACTGCTGACAGGACTCTC 81 82 TGCAGGaGaAGAACACTGGTTTTAACACTGCAGAGACTGGAaGATTTMAGTGGATTATACCAAGCAGTGTGAGGatgtgg 162 at on 2 3 L L G L Q V V T I C V F L Q V P G C F P S C L L I T G G S 29

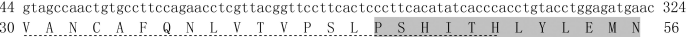
25 cgcatcagcgagattaactctacctccctgtcaggcctcgagcagctgcaggagctagacctgggacaacagtatgtgcca 405 46 cttgtgetcagose

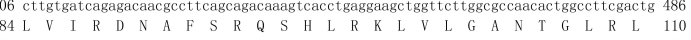

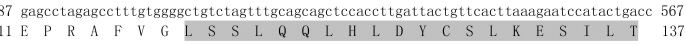

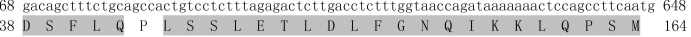
49 ttctttgcaacatgactaatt tgaaagatgtgaatctgaagctgaacaaaattgacaaaatatgtgaatcagatctggtt 729

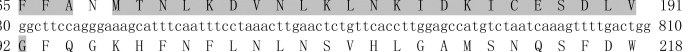
811 cagaaatgtgggaatcctttcagaggaatgtctttccagaaactcgacctatcctacaacgggttcagcgtgcgtagatcg 891

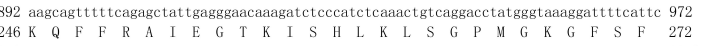
973 agaaatctcctgatccagaccgcagcacgtttgagggcttacacaacagttctctccacaccttagatctgtccaaaaac 1053 300 R I F A L Q Q G V F S P L K E V V S I D V S Q N S V N 326 35 cagatacacagaaatgcctttgaaggtcttcagggtcatttaaaaatgctcaacctgtcacacaacctgcttggggaaatc 1215 16 tattct tacacttttgct tctctgacaaaccttaaagtgt tagat tgtct tacaatcacat tggtgttctgggt tataac 1296

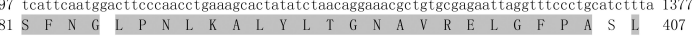
378 cctagt tagat tttctcatgttgaatgacaataagt tgacggcatcatcagtgagcagaatcactcagt ttgccagtaat 1458 159 attatcetcon $L$

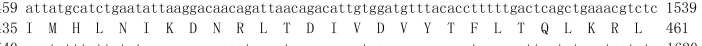
540 cagtatttcttctatggaggaacacaatcagatggagcacgctcagcagacaagcgtcagcaattggtctgaataatctc 1620
462 Q Y F F Y G G N T I R W S T L S R Q A S A I G L N N L 488 $\begin{array}{llll}21 & \text { caagtectggatcttcacagcagctccetgcagtctattegtctcagggcaaatgtctgaatctgtttgacaatcttgga } 1701 \\ 89 \text { Q V L D L H S S S L Q S I W S Q G K C L N L F D N L G } & 515\end{array}$

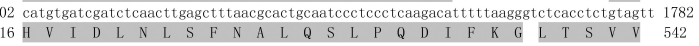
78 cagatggacctctcatccaacgccttgacgtatctccagcctggtgtattacccaaaagtctgaaaatactcaacctctcc 1863 64 aacaacttcatagcctccccagacccagacgctttccgctctctcaagctcctcaacctgggaat gaaccgattcact $\quad 569$ \begin{tabular}{llllllllll}
570 & N N F I A S P D P D D A F R S L K L L N L G M N R F H C & 596 \\
\hline
\end{tabular} 945 gacacaaacctaaagagttttceggettggatgaccgagaccaatgtcaccttcttgagtcctgttcaggagctcagatgt 2025
597 D T N L K S F P A W M T E T N V T F L S P V Q E L R C 623 26 gaatttccatctgctttctacaaggttcctctgttaaat tactctgctcagctcacacagcagtaaAAGCATTTAGGATGT 2106

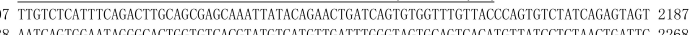
188 AATCAGTGGAATAGGGCACTGGTGTCACGTATGTCATGTTGATTTGGGTAGTGCAGTCACATGTTATCCTCTAACTGATTC 2268

(1)

Figure 1. The full-length cDNA and deduced amino acid sequences of ToTLR5M (A) and ToTLR5S (B). The leucine-rich repeat (LRR) and LRR-NT domains are highlighted in light gray and by dotted lines, respectively. The LRR-CT domains are underlined in ToTLR5S (B). The transmembrane region is indicated by box and the Toll/IL-1 receptor (TIR) domain is marked with gray; termination codon is indicated with "**". 
A

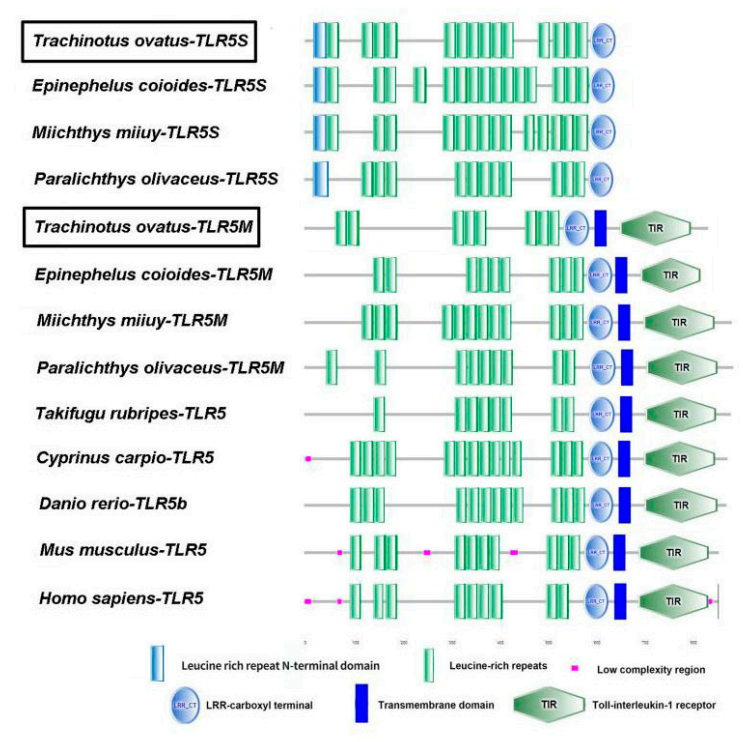

B
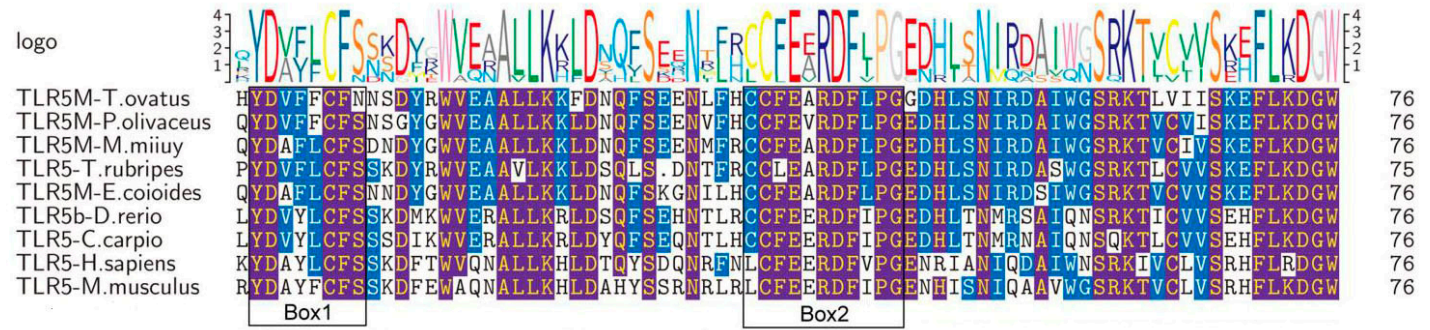

$\log 0$

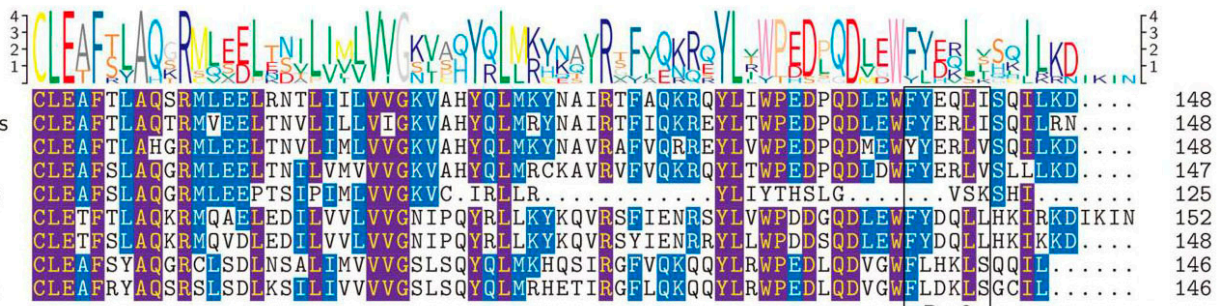

冈 non conserved

$\geq 50 \%$ conserved

Figure 2. The domain features of the membrane form of TLR5 (TLR5M) and the soluble form of TLR5 (TLR5S) among vertebrates. (A) Multiple alignment of TLR5 deduced amino acid sequences. LRR represents leucine-rich repeats, red represents low-complexity region, LRR-CT represents LRR C-terminal region, blue represents transmembrane region, TIR represents Toll/interleukin-I receptor domain. (B) The amino acid sequence alignment of TLR5 TIR domains in various species. The GenBank accession numbers are shown in Table S1. 


\subsection{Tissue Expression of ToTLR5M and ToTLR5S}

To confirm the role of ToTLR5M and ToTLR5S in healthy fish, we used qRT-PCR to detect the mRNA expression levels in 10 tissues (Figure 3). Two ToTLRs were constitutively expressed in all tissues analyzed, with varied expression levels being observed. ToTLR5M is highly expressed in the intestine, kidney, and liver, followed by the blood, skin, gill, brain, and stomach, with lower expression levels being observed in the spleen and white muscle $(p<0.05)$. However, ToTLR5S is highly expressed in the blood, kidney, spleen, and skin, followed by the intestine, liver, brain, and white muscle, with lower mRNA levels being observed in the gill and stomach $(p<0.05)$.

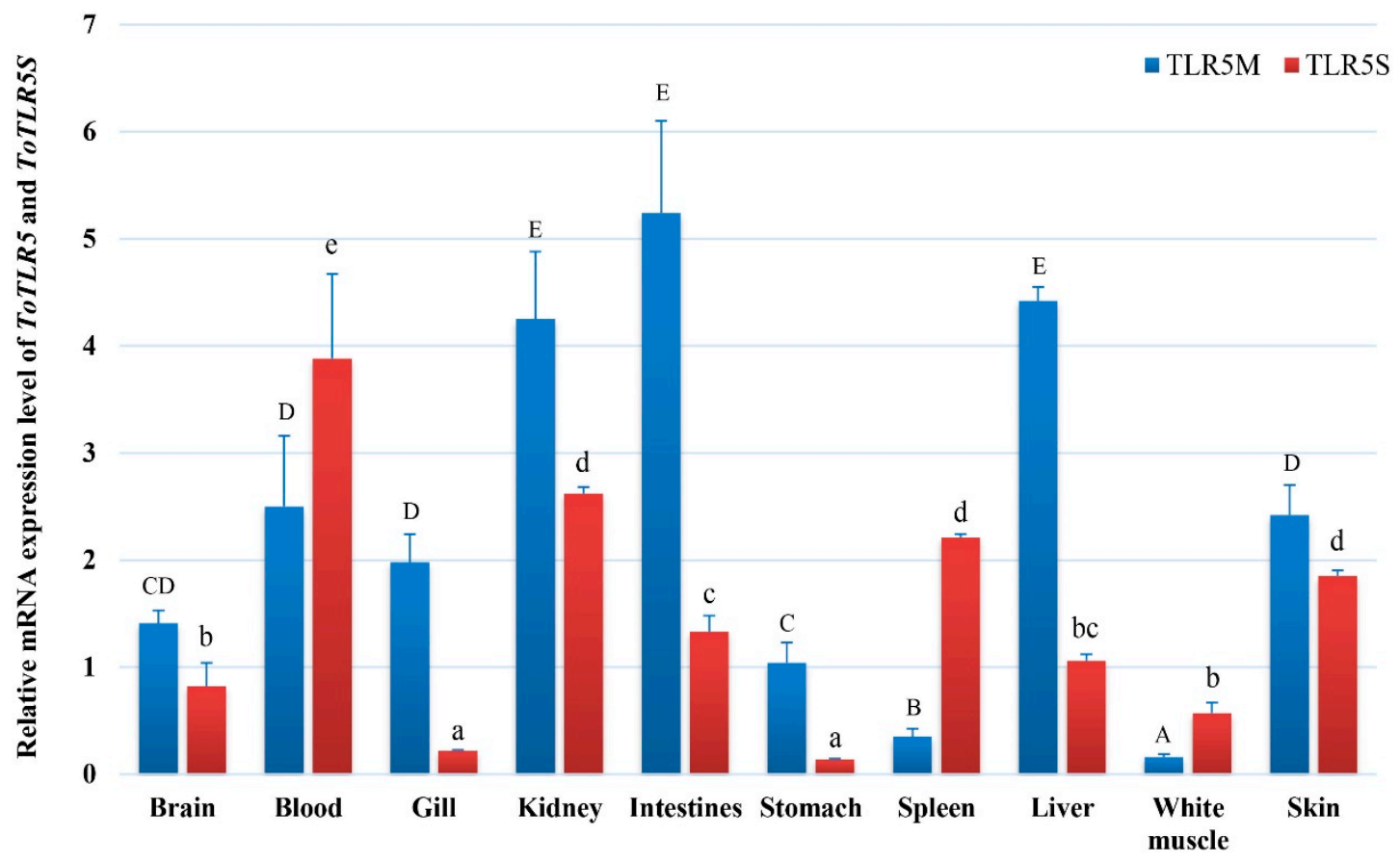

Figure 3. The tissue expression of the ToTLR5M and ToTLR5S genes. The tissues included kidney, liver, stomach, spleen, intestine, brain, skin, gill, muscle, and blood. Elongation factor 1 alpha $(E F-1 \alpha)$ acted as an internal reference to calibrate the cDNA templates. Mean \pm standard error (SE) $(n=3)$ of each mRNA quantity was shown for each tissue examined. Different uppercase or lowercase letters indicate significant differences $(p<0.05)$.

To further investigate the role of ToTLR5M (Figure 4) and ToTLR5S (Figure 5) in the immune response, we also used qRT-PCR to investigate gene expression in response to poly(I:C), LPS, and flagellin challenges. In comparison to the control group, the mRNA levels of ToTLR5M were markedly increased in response to poly(I:C), LPS, and flagellin challenges in the immuneand nonimmune-related tissues, suggesting the possible role of ToTLR5M in defense against pathogenic microbes. As shown in Figure 4, ToTLR5M transcription was more sensitive in the liver, blood, and kidney than in the intestine, skin, and muscle, suggesting a dramatic increase of 7.92-fold, 8.73-fold, and 9.07-fold in the liver, blood, and kidney after infection with LPS, respectively, compared to the control. Nevertheless, there was a dramatic increase of 2.78-fold, 2.73-fold, and 2.55-fold in the intestine, skin, and muscle after infection with poly(I:C), flagellin, and poly(I:C), respectively, compared to the control.

In comparison to the control group, ToTLR5S expression was upregulated by poly(I:C), LPS, and flagellin challenges in the immune- and nonimmune-related tissues (Figure 5). Notably, ToTLR5S was more responsive in the liver, skin, intestine, and kidney than in the other two tissues, showing remarkable increases of 213.64-fold, 93.08-fold, 38.16-fold, and 42.65-fold in the liver, skin, intestine, and kidney after challenge with LPS, flagellin, flagellin, and flagellin, respectively, compared to the 
control. Nevertheless, compared to the control, there was a dramatic increase of 5.85-fold and 3.15-fold in the blood and muscle after infection with flagellin and poly(I:C), respectively.
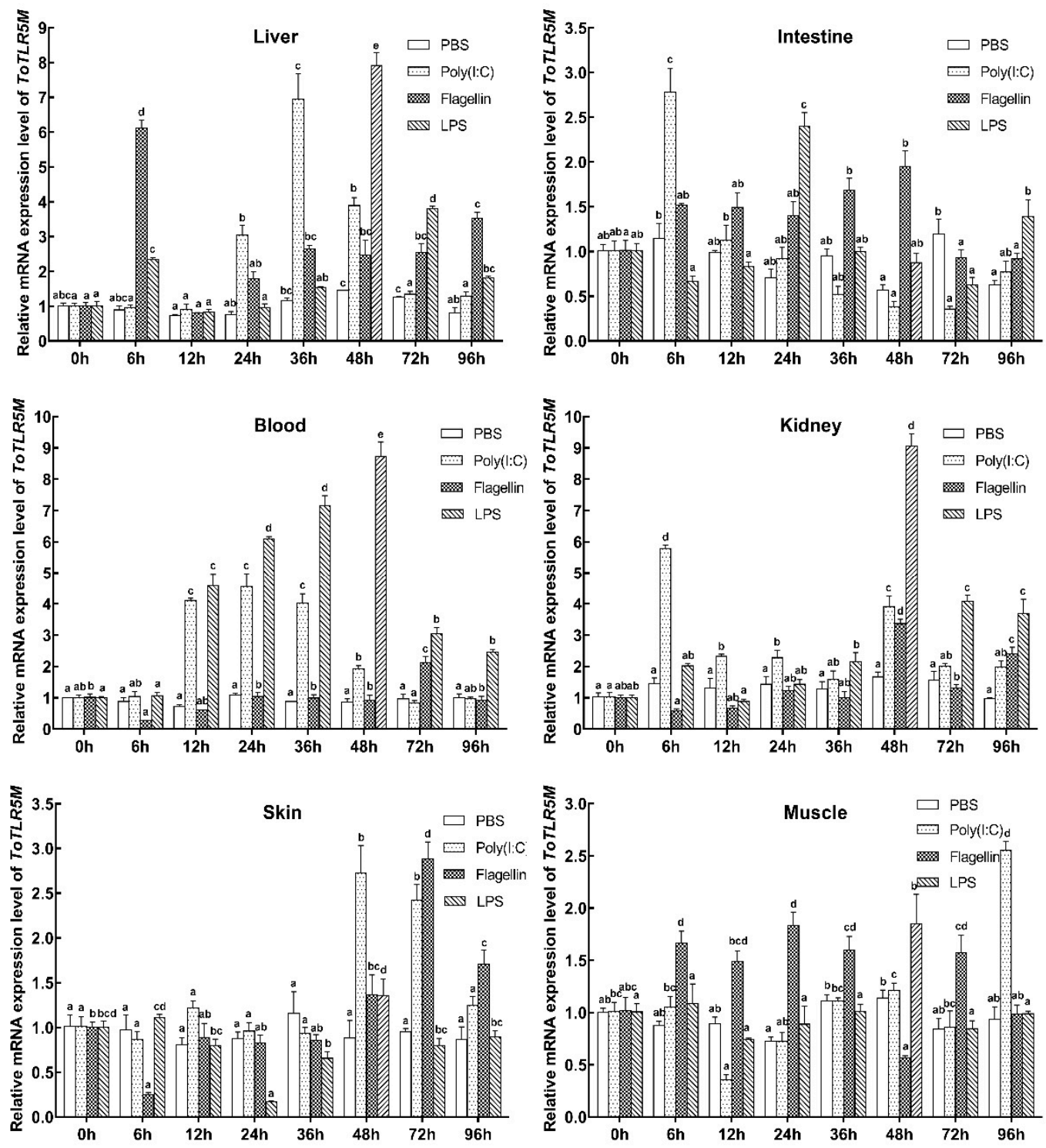

Figure 4. ToTLR5M expressions in different tissues (liver, kidney, intestine, skin, muscle, and blood) after phosphate-buffered saline (PBS), flagellin, poly(I:C), and LPS challenge. EF-1 $\alpha$ acted as an internal control to calibrate the cDNA templates. All data are expressed as mean $\pm \mathrm{SE}$. Different letters show significant differences $(p<0.05)$. 

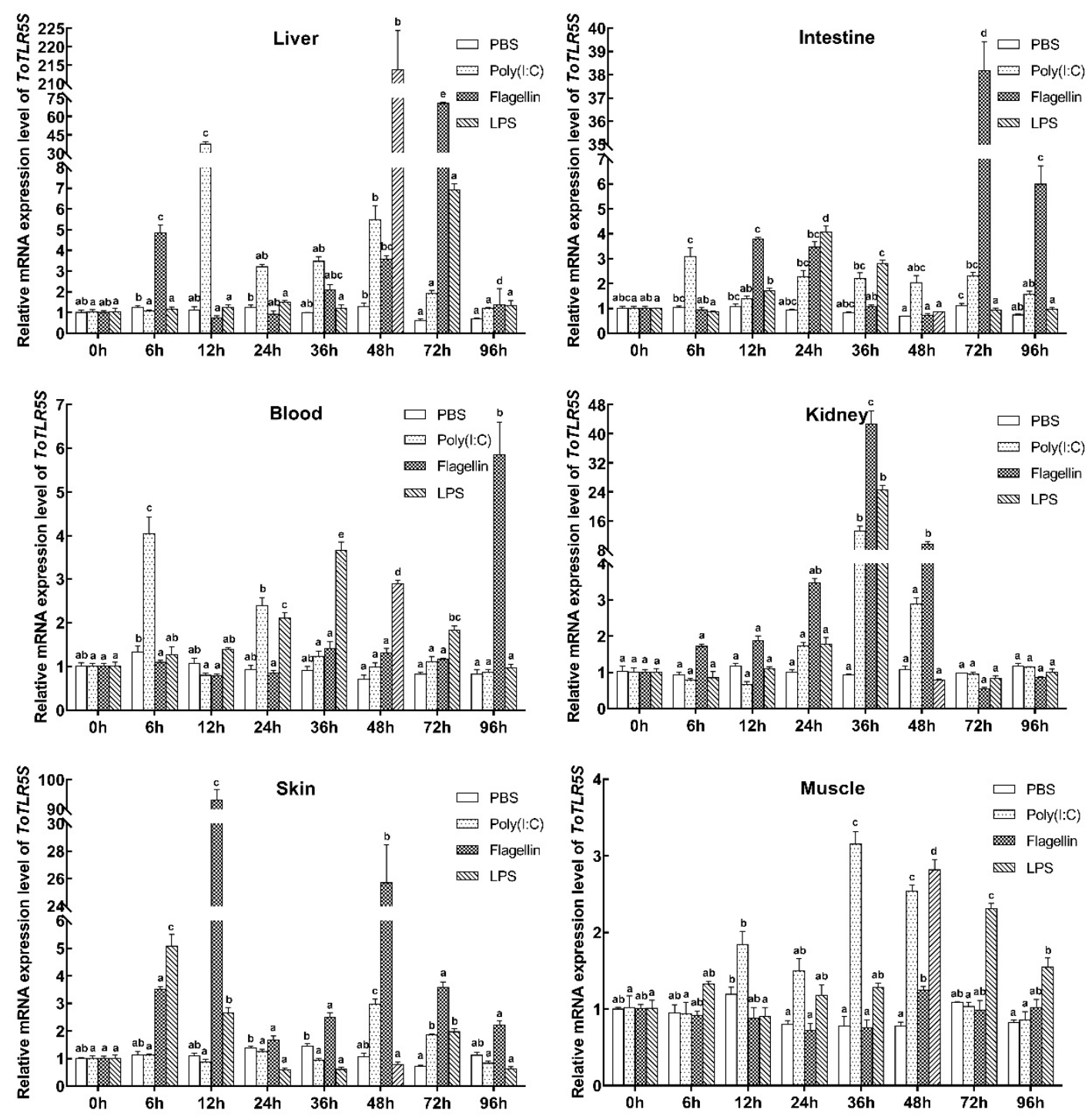

Figure 5. ToTLR5S expressions in different tissues (liver, kidney, intestine, skin, muscle, and blood) after PBS, flagellin, poly(I:C), and LPS challenge. EF-1 $\alpha$ acted as an internal control to calibrate the cDNA templates. All data are expressed as mean \pm SE. Different letters show significant differences $(p<0.05)$.

\subsection{Promoter Activity of Two ToTLR5s}

The $5^{\prime}$-flanking fragment of two ToTLR5 genes lacked both the TATA box and CAAT box. The transcription factor binding sites for C/EBPalpha, C/EBPbeta, Sp1, AP-1, NF-1, Oct-1, GATA-1, NF- $\mathrm{kB}$, ICSBP, c-Rel, and IRF-1 could be predicted in the 5 -flanking sequence of the ToTLR5M gene (Figure S2A). Deletion of the sequences from -1827 to $-1566 \mathrm{bp},-813$ to $-501 \mathrm{bp},-309$ to $-120 \mathrm{bp}$, and -120 to $+1 \mathrm{bp}$ of ToTLR5M significantly decreased the relative luciferase activity, indicating that transcription factors of NF-kB, GATA-1, C/EBPalpha, NF-1, Oct-1, and ICSBP played a positive role in the regulatory effect. Furthermore, there was no significant difference after the deletion of the sequences from -1566 to $-813 \mathrm{bp}$. However, the relative luciferase activity was increased by deleting the sequences of -501 to $-309 \mathrm{bp}$ (Figure 6A). 
A

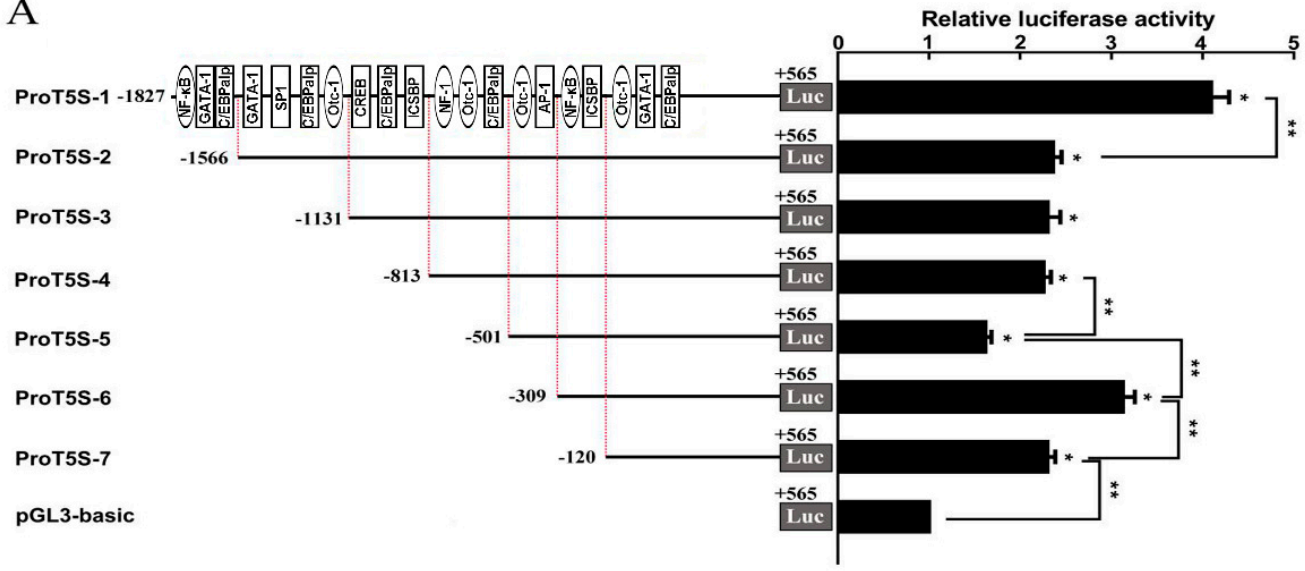

B

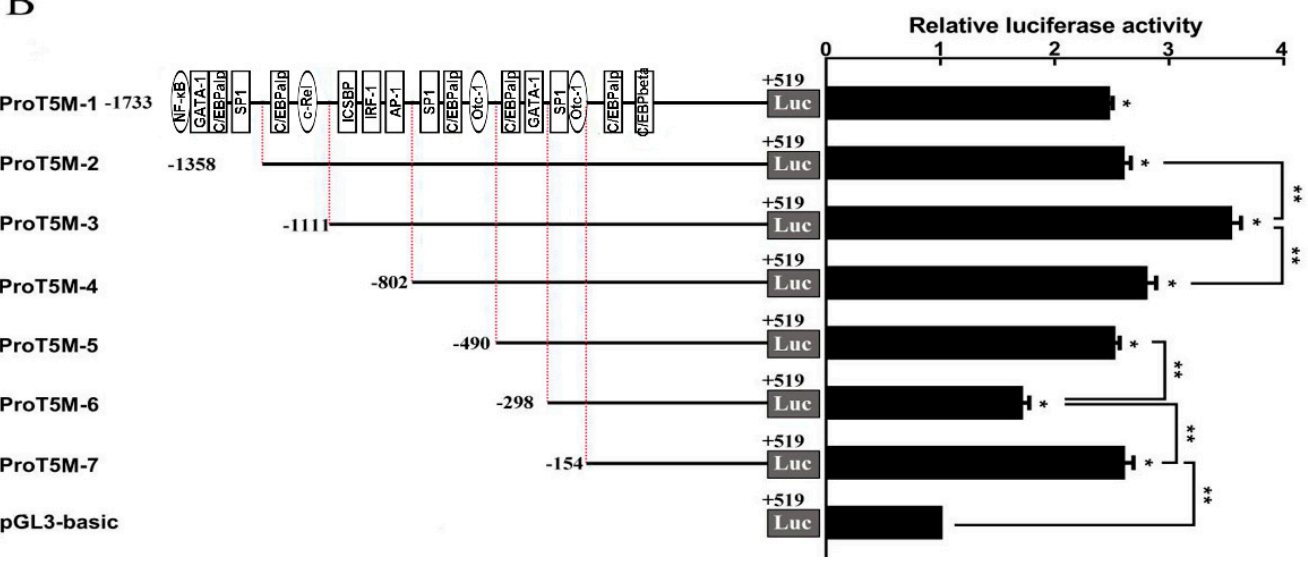

Figure 6. Promoter activity analysis of ToTLR5M (A) and ToTLR5S (B). (A) Seven recombinant plasmids, denoted as ProT5M-1 ( -1827 to +565$)$, ProT5M-2 $(-1566$ to +565$)$, ProT5M-3 $(-1131$ to +565$)$, ProT5M-4 (-813 to +565), ProT5M-5 (-501 to +565), ProT5M-6 ( -309 to +565$)$, and ProT5M-7 (-120 to +565) were constructed and transfected into Trachinotus ovatus snout tissue (GPS) cells. (B) Seven recombinant plasmids, denoted ProT5S-1 $(-1733$ to +519$)$, ProT5S-2 $(-1358$ to +519$)$, ProT5S-3 $(-1111$ to +519$)$, ProT5S-4 ( -802 to +519$)$, ProT5S-5 $(-490$ to +519$)$, ProT5S-6 $(-298$ to +519$)$, and ProT5S-7 $(-154$ to +519$)$ were constructed and transfected into GPS cells. Different color boxes indicate binding sites located in different truncation regions. All data are expressed as mean $\pm \mathrm{SE}$ in the picture $(n=5)$. * indicates significant differences $(p<0.05) .{ }^{* *}$ indicates extremely significant differences $(p<0.01)$.

The transcription factor binding sites for C/EBPalpha, C/EBPbeta, C/EBPgamma, Sp1, AP-1, Oct-1, GATA-1, IRF1, NF-kB, ICSBP, NF-1, Sox-2, SGF-3, CREB, and NF-K could be predicted in the 5 '-flanking sequence of the ToTLR5M gene (Figure S2B). Deletion of the sequences from -1111 to $-802 \mathrm{bp}$, -490 to $-298 \mathrm{bp}$, and -154 to $+1 \mathrm{bp}$ of ToTLR5S significantly decreased the relative luciferase activity, indicating that the transcription factors ICSBP, IRF1, AP-1, GATA-1, C/EBPalpha, and C/EBPbeta played positive roles in the transcriptional regulatory system. Moreover, there was no significant difference after the deletion of the sequences from -1733 to $-1358 \mathrm{bp}$ and -802 to $-490 \mathrm{bp}$. However, the relative luciferase activity was increased by deleting the sequences of -1358 to $-1111 \mathrm{bp}$ and -298 to $-154 \mathrm{bp}$ (Figure 6B).

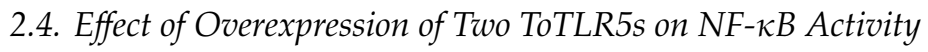

To further confirm the interaction of the two ToTLR5s with NF- $\kappa B$, we determined the influence of ToTLR5M or ToTLR5S overexpression on NF- $\kappa B$ transcription. We performed a luciferase reporter assay using golden pompano Trachinotus ovatus snout tissue (GPS) cells transiently cotransfected with NF-kB reporter vector and ToTLR5M-pcDNA3.1 or ToTLR5S-pcDNA3.1 individually or both 
ToTLR5M and ToTLR5S together. The results showed that overexpression of ToTLR5M or ToTLR5S can significantly enhance NF-KB activity $(p<0.01)$, and overexpression of both ToTLR5M and ToTLR5S can also significantly enhance NF-кB activity $(p<0.01)$ (Figure 7$)$. The relative luciferase activity of $N F-\kappa B$ was highest with cotransfection of ToTLR5M.

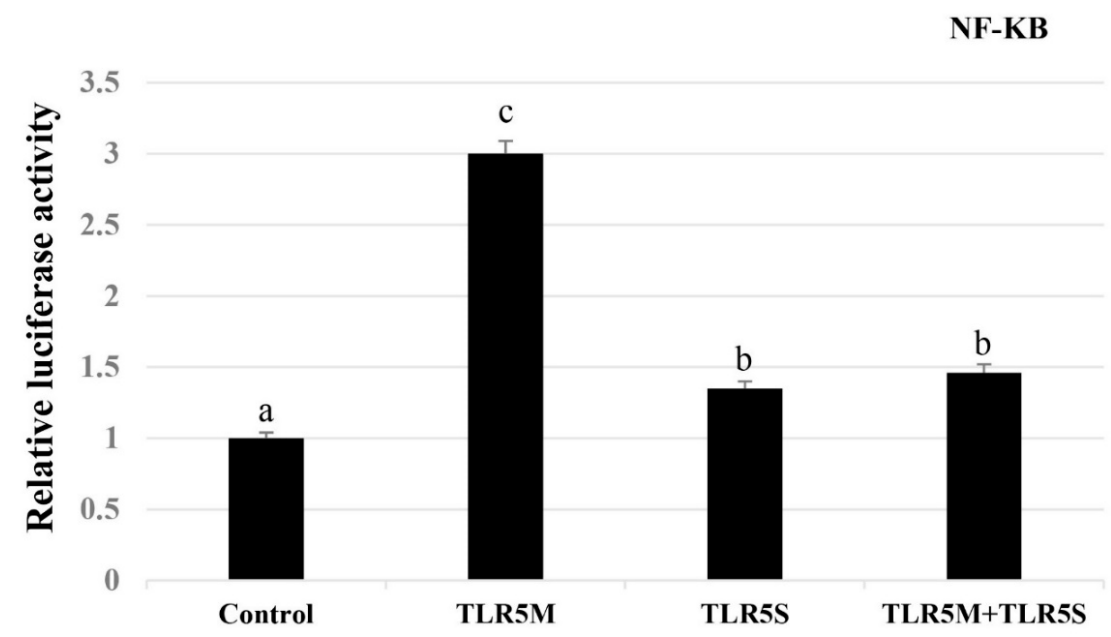

Figure 7. Overexpression of two ToTLR5 genes altered the expression levels of NF- $\mathrm{kB}$. The cells were transfected with an empty vector or ToTLR5s-pcDNA3.1. Each of them was co-transfected with an $\mathrm{NF}-\mathrm{kB}$ reporter plasmid. All data are expressed as mean \pm SE. Different letters show significant differences $(p<0.05)$.

\subsection{Binding of Two rToTLR5s to Bacteria and PAMPS}

The two rToTLR5 proteins were expressed in the pET-sumo vector in Escherichia coli (Rosetta DE3). SDS-PAGE (Figure 8A) and Western blotting analysis (Figure 8B) showed that recombinant ToTLR5M and ToTLR5S proteins were successfully expressed (Figure 8). The recombinant proteins were purified using Ni-NTA resin. The observed molecular weights of rToTLR5M ( $76 \mathrm{kDa})$ and rToTLR5S $(\approx 85 \mathrm{kDa})$ were close to the predicted molecular weights of the proteins.

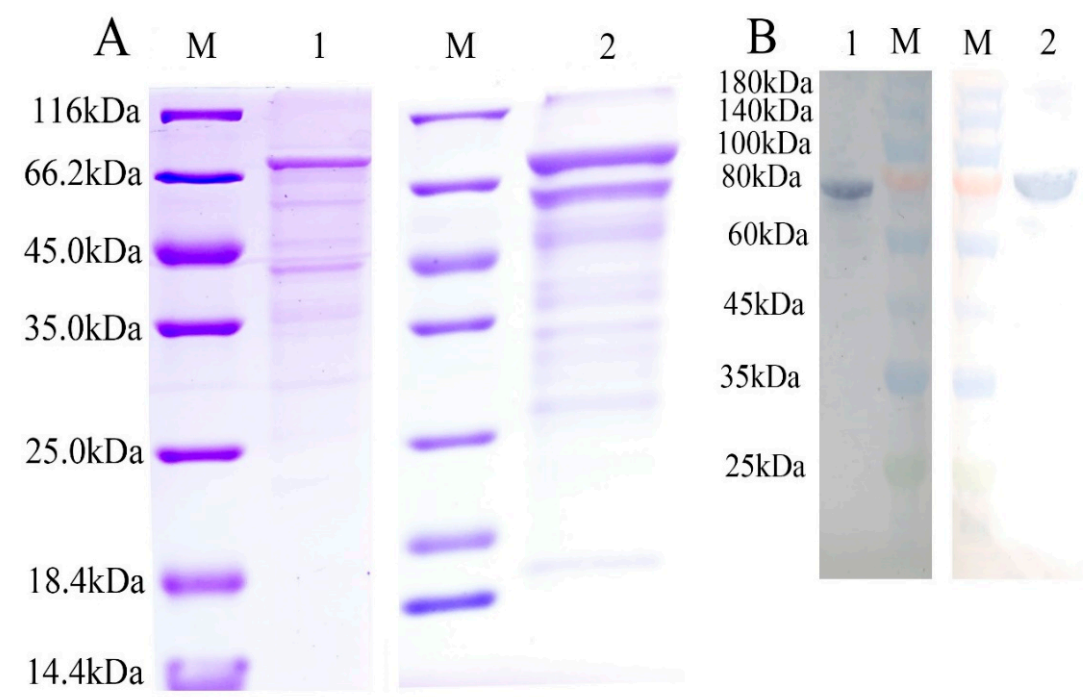

Figure 8. SDS-PAGE (A) and Western blot (B) analysis of two purified recombinant ToTLR5s. (A) Lane M: standard protein marker; lane A1: purified recombinant ToTLR5M; lane A2: purified recombinant ToTLR5S. (B) Lane M: standard protein marker; lane B1: rToTLR5M; lane B2: rToTLR5S. 
The binding of purified two rToTLR5s to bacteria and PAMPs was analyzed by ELISA (Figure 9). The binding activity of two rToTLR5s with Gram-negative bacteria and Gram-positive bacteria was positive, and the binding index was positively correlated with the amount of protein. The binding activity of two ToTLR5 extracellular recombinant proteins to four different PAMPs was positive. rToTLR5M had strong binding activity to flagellin, poly(I:C), and PGN but weak binding activity to LPS (Figure 9A). rToTLR5S had strong binding activity to flagellin and LPS but weak binding activity to poly(I:C) and PGN (Figure 9B). Moreover, rToTLR5M had strong binding activity to Photobacterium damselae but weak binding activity to Aeromonas hydrophila and Staphylococcus aureus (Figure 9C). rToTLR5S had strong binding activity to Vibrio vulnificus and E. coli but weak binding activity to Aeromonas hydrophila (Figure 9D).
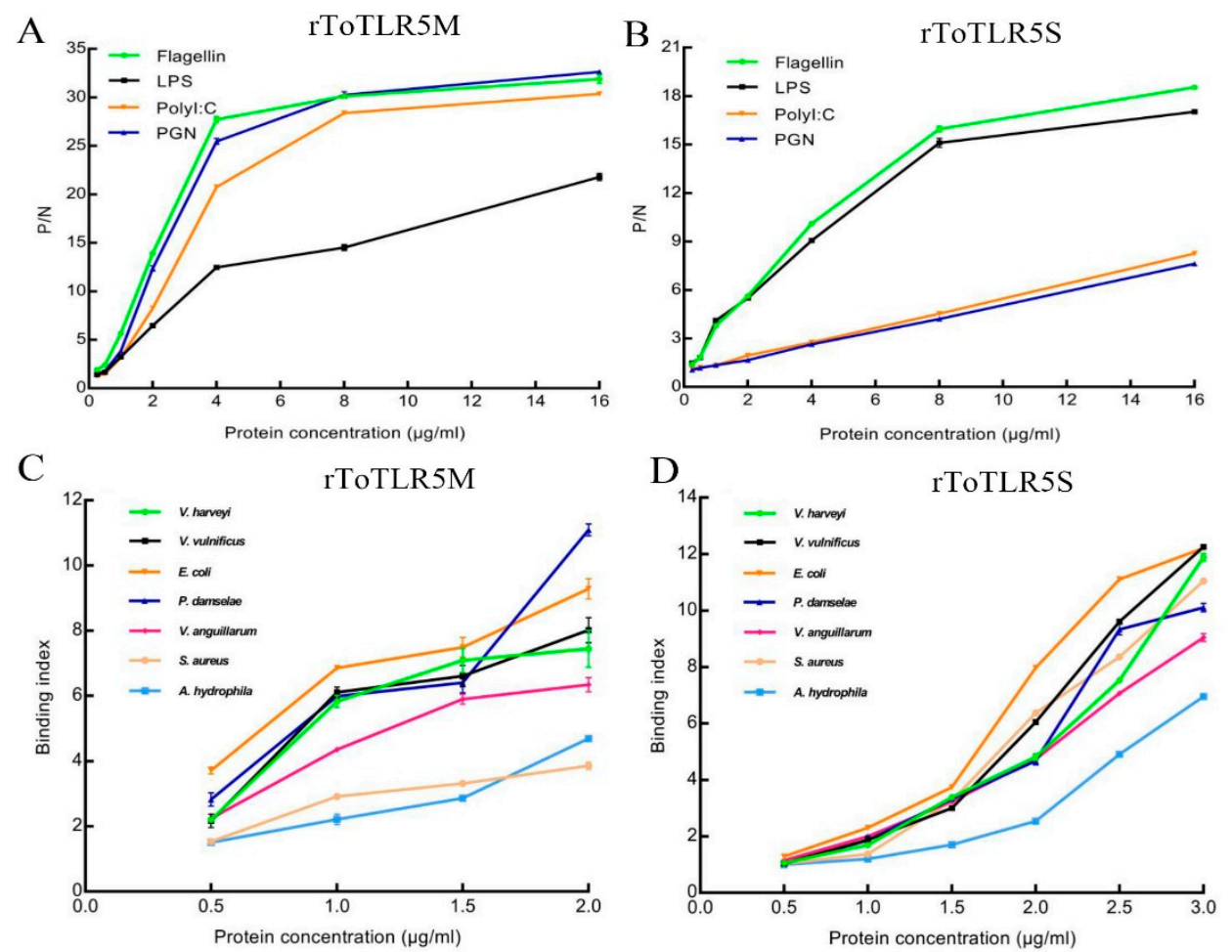

Figure 9. ELISA analysis of the interaction between rToTLR5M $(\mathbf{A}, \mathbf{C})$ and rToTLR5S $(\mathbf{B}, \mathbf{D})$ to pathogen-associated molecular patterns (PAMPs) $(\mathbf{A}, \mathbf{B})$ and bacteria $(\mathbf{C}, \mathbf{D})$, respectively. The microtiter plates were coated with PAMPs and bacteria, and then incubated with different concentrations of recombinant protein. The interaction between protein and PAMPs/bacteria were detected by composite anti-His polyclonal antiserum at $450 \mathrm{~nm}$. Results were representative of an average of three experiments.

\section{Discussion}

The TLR family is highly evolutionarily conserved, and TLRs in most mammals are homologous to those in fish [8]. TLR5 is believed to be the only TLR that binds to the protein PAMP known as bacterial flagellin [11]. The synergistic role of the TLR5 membrane form (TLR5M) and TLR5 soluble form (TLR5S) has been reported in a study on Onchorhynchus mikiss [16]. This system is regarded as a unique system in teleost fish. In this study, we cloned both the membrane and soluble form of TLR5 from T. ovatus. ToTLR5M, similar to mammalian TLR5, consists of extracellular LRRs, a transmembrane domain, and an intracellular TIR domain. The lack of transmembrane and intracellular TIR domains in ToTLR5S suggests that it can be secreted from cells, as well as other TLR5S proteins in teleost fish [17,18,21,27]. The structural characteristics of these two ToTLR5s were similar to those of the TLR5 gene in other teleosts [27]. The extracellular LRR domain plays an important role in the recognition of pathogen components on the surface of immune cells. The binding regions of LRR could form on the concave 
$\beta$-face of LRR by a combination of inserts and specific binding surfaces [31,32]. These LRRs seem to be candidates for the flagellin-binding region in two ToTLR5s. The positions of LRR insertions are highly conserved in metazoan (Figure 2A). Therefore, ToTLR5 might be functionally capable of responding to the metazoan TLR5 agonist flagellin. Moreover, in the majority of species, the number of extracellular leucine repeat sequences in TLR is different, which may be attributed to the diversity of species. The intracellular TIR domain of TLR is mainly responsible for signal transmission, including three highly conserved motifs, Box1, Box2 and Box3, in which Box1 and Box2 are associated with signal transduction, whereas Box3 is associated with TLR localization in cells [33].

The tissue expression profile of ToTLR5M mRNA supports previous studies of TLR5M in other fishes, including I. punctatus, Pelteobagrus fulvidraco, and O. fasciatus, which have generally shown similar patterns of constitutive expression in most tissues, with higher expression being observed in the liver $[21,34,35]$. However, TLR5M had the highest mRNA level in the skin followed by the spleen and kidney in Epinephelus coioides [18]. Moreover, TLR5S expression was the highest in the liver followed by the spleen in E. coioides, and the transcription of TIL5S was higher in the liver and head kidney than in other tissues in M. miiuy [27] and Scophthalmus maximus [36], which was different from the results in T. ovatus. Liver macrophages are present in the liver, and moreover the kidney and spleen are the main lymphoid organs of fish. These three important tissue sites are involved in the immune response of the body. The expression patterns of the TLR5 gene in various tissues suggested that it plays an important role in the immune monitoring system of these fish, and different tissue expression patterns may be related to species type, individual size, or stage of development.

Previous studies have demonstrated that poly(I:C), LPS, and flagellin can cause defense responses against pathogens in pompano [37-41]. Many studies have found that these PAMPs can induce the expression of TLR5M or TLR5S genes in immune-related tissues (liver, intestine, blood, kidney, and skin) $[17,20,21,36,42,43]$. For example, poly(I:C) can increase the mRNA levels of Carassius auratus TLR5 [42]; LPS can induce the expression of Pampus argenteus TLR5 [43] and S. maximus TLR5M [36]; and flagellin can upregulate the O. fasciatus, P. olivaceus, and C. idelus TLR5 expression $[17,20,21]$. After injections with poly(I:C), LPS, and flagellin, ToTLR5M and ToTLR5S expression levels were upregulated in the tissues of the immune system, especially in the liver and kidney, which is consistent with TLR5 expression patterns observed in other fish, such as O. fasciatus, P. olivaceus, C. idelus, S. maximus, C. auratus, and P. argenteus $[17,20,21,36,42,43]$.

The ToTLR5M promoter region was located in the $-1733 \mathrm{bp}$ to $+519 \mathrm{bp}$ region, which included several transcription factor binding sites, such as C/EBP, Sp1, AP-1, Oct-1, NF-KB, c-Rel, and IRF1. The cis-acting elements may be located between -1827 to $-1566 \mathrm{bp},-813$ to $-501 \mathrm{bp}$, and -309 to $+1 \mathrm{bp}$, which contain NF-кB, GATA-1, C/EBPalpha, NF-1, Oct-1, and ICSBP. This region was similar to that of O. fasciatus [21], while the binding sites of AP-1, SP1, SP3, and NF-KB existed in the human TLR5M promoter region, and SP1/3 binding sites significantly enhanced TLR5 promoter activity [44]. Moreover, in ToTLR5S, the cis-acting elements may be located between -1111 to $-802 \mathrm{bp},-490$ to $-298 \mathrm{bp}$, and -154 to +1 , which contain ICSBP, IRF1, AP-1, GATA-1, C/EBPalpha, and C/EBPbeta. In Paralichyths olivaceus, the TLR5S promoter region contained binding sites for such factors as CEBP, AP-1, and NF-KB, and Ap-1 and NF- $\mathrm{KB}$ binding sites significantly enhanced TLR5S promoter activity [45]. The transcriptional regulatory mechanisms of TLR5M between Trachinotus ovatus and mammals exhibited both similarities and differences, while the TLR5S gene specific to fish had similar activity and was regulated by a variety of transcriptional elements. Future experiments require further analysis of specific transcriptional binding sites.

NF-кB plays an important role in the TLR signaling pathway, and overexpression of C. idelus TLR18 and TLR5 has been shown to significantly increase NF-кB activity $[42,46]$. Furthermore, the TLR5M signaling in response to flagellin abduction in Onchorhynchus mikiss is magnified through interaction with the TLR5S in a positive loop feedback [8]. In the present study, overexpression of ToTLR5M significantly activated NF-кB expression followed by overexpression of ToTLR5S or ToTLR5M and 
ToTLR5S. It is possible that ToTLR5M and ToTLR5S have antagonistic effects on the activation of the NF-кB signaling pathway, suggesting that the interactions of TLR5M and TLR5S were species-specific. ELISA was used to detect the binding activity of purified protein with bacteria, and it was found that the ToTLR5M and ToTLR5S recombinant proteins containing LRR domains had notable binding activity to Gram-positive/negative bacteria. These results suggest that ToTLR5M and ToTLR5S might recognize and combine pathogenic molecular patterns of some bacteria and play an important role in preventing the infection of Gram-positive/negative bacteria.

The ToTLR5M recombinant protein primarily recognizes the bacterial components peptidoglycan and flagellin and the viral equivalent poly(I:C), while the ToTLR5S recombinant protein primarily recognizes the bacterial components flagellin and liposaccharide. TLR5, located on cell membranes in mammals, primarily recognizes bacterial flagellin [11,47]. Pathogenic bacteria could be identified by TLR5 proteins from fishes such as E. coioides [18], M. miiuy [27], and I. punctatus [34]. The two recombinant proteins have different degrees of binding activity to Gram-negative bacteria and Gram-positive bacteria, indicating that ToTLR5M and ToTLR5S play an important role in antibacterial immune reactions. Moreover, the binding activity of different PAMPs indicated that the extracellular recombinant proteins could participate in the TLR ligand recognition process of pompano. The main ligands recognized by different proteins are different, but the specific binding and mechanism of action warrant further study.

In summary, we identified a membrane form and a soluble form of ToTLR5. Both genes displayed conserved sequence characteristics with those of other fish. The expression analysis of ToTLR5M and ToTLR5S after stimulation with PAMP containing LPS, poly(I:C), and flagellin indicated that the two ToTLR5s played a role in antibacterial immunity. Furthermore, we demonstrated clear associations between NF-KB and the two ToTLR5s promoters, as well as the positive regulatory functions of the two ToTLR5s in NF-KB transcription. ToTLR5M and ToTLR5S were displayed as PRRs that ensured specific binding to various PAMPs and bacteria. The results of the present study indicate that these two ToTLR5s are involved in the immune response to pathogen invasion.

\section{Materials and Methods}

\subsection{Ethics Statement}

In the present study, all trials were approved by the Animal Care and Use Committee of South China Sea Fisheries Research Institute, Chinese Academy of Fishery Sciences (no. SCSFRI96-253, approval date: 11 March 2019) and performed according to the guidelines and regulations established by this committee.

\subsection{Fish and Challenge Experiments}

Juvenile fish (average weight of $40 \mathrm{~g}$ ) were purchased from Linshui Marine Fish Farm (Hainan, China). The fish were maintained in fresh seawater at approximately $28{ }^{\circ} \mathrm{C}$ with $35 \%$ salinity and in dissolved oxygen $>6 \mathrm{mg} / \mathrm{L}$ and were raised 1 week before the trial. Tissue samples (stomach, intestine, kidney, liver, spleen, brain, skin, gill, white muscle, and blood) were collected from six healthy pompano, promptly frozen in liquid nitrogen, and then stored at $-80^{\circ} \mathrm{C}$ until use.

The stimulation groups were intraperitoneally injected with poly(I:C) $(200 \mu \mathrm{g} / \mathrm{mL}, 200 \mu \mathrm{L})$, flagellin $(1 \mu \mathrm{g} / \mathrm{mL}, 200 \mu \mathrm{L})$, or LPS $(50 \mu \mathrm{g} / \mathrm{mL}, 200 \mu \mathrm{L})$, and the control group was injected with phosphate-buffered saline (PBS, $200 \mu \mathrm{L}$ ). The induction experimental program was described in previous studies [37]. Pompano were anaesthetized using MS222 (0.1 g. $\mathrm{L}^{-1}$; Sigma, Alcobendas, Spain) in all groups before tissue sampling. Six tissues (liver, intestine, blood, kidney, skin, and muscle) were harvested from five fish per group at $0 \mathrm{~h}, 6 \mathrm{~h}, 12 \mathrm{~h}, 24 \mathrm{~h}, 36 \mathrm{~h}, 48 \mathrm{~h}, 72 \mathrm{~h}$, and $96 \mathrm{~h}$ after the challenge, immediately frozen in liquid nitrogen, and then stored at $-80^{\circ} \mathrm{C}$ until use. 


\subsection{RNA Extraction and Gene Cloning}

Pompano kidney tissues were used to isolate total RNAs $(1 \mu \mathrm{g})$ by the HiPure Fibrous RNA Plus Kit (Magen, Guangzhou, China). Total RNA was treated with RNase-free DNase I at $37^{\circ} \mathrm{C}$ for $30 \mathrm{~min}$ and then used to synthesize cDNA by random hexamer primers (Cloned AMV First-Strand cDNA Synthesis Kit, Invitrogen, Carlsbad, CA, USA). The quantity and quality of the extracted RNA were determined by a NanoDrop 2000 spectrometer (Thermo Fisher Scientific, Waltham, MA, USA) and 1\% agarose gels. The predicted sequences of ToTLR5M and ToTLR5S were acquired from pompano genomic data [48]. Moreover, gene-specific primers were designed to amplify the cDNA and genome sequences of two genes that were assembled by SeqMan software of the LaserGene package (DNASTAR, Inc., Madison, WI, USA) (Table 1).

\subsection{Bioinformatics}

Amino acids of two ToTLR5s were used as queries to seek orthologous genes in the NCBI database (http://blast.ncbi.nlm.nih.gov/Blast.cgi). All available TLR5 structures and sequences were provided by Genome Browser (http://genome.ucsc.edu/cgi-bin/hgBlat) and Ensembl (http://asia.ensembl.org/). ClustalW2 (http://www.ebi.ac.uk/Tools/msa/clustalw2/) was used to blast different TLR5 mature peptide sequences. Compute $\mathrm{pI} / \mathrm{Mw}$ software (http://web.expasy.org/protparam/) was used to calculate the theoretical isoelectric points and molecular weights.

\subsection{Cloning of the $5^{\prime}$-flanking Sequence and Its Promoter Activity}

Total genomic DNA was extracted from the muscle tissue of pompano according to Sun et al. (2013) [49] and used for cloning of the candidate promoter. To define the core promoter region within the cloned $5^{\prime}$-flanking sequence of ToTLR5M and ToTLR5S, we amplified seven different promoter regions from ToTLR5M and ToTLR5S by specific primers with Hind III and Kpn I restriction sites, respectively (Table 1). Subsequently, the seven truncated fragments of ToTLR5M (denoted as ProT5M-1 ( -1827 to +565$)$, ProT5M-2 ( -1566 to +565$)$, ProT5M-3 $(-1131$ to +565$)$, ProT5M-4 $(-813$ to +565$)$, ProT5M-5 ( -501 to +565$)$, ProT5M-6 $(-309$ to +565$)$, and ProT5M-7 $(-120$ to +565$))$ were subcloned into the pGL3-basic luciferase reporter plasmid (Promega, WI, USA). Moreover, the seven truncated fragments of ToTLR5S (denoted as ProT5S-1 (-1733 to +519), ProT5S-2 (-1358 to +519), ProT5S-3 $(-1111$ to +519), ProT5S-4 (-802 to +519), ProT5S-5 (-490 to +519), ProT5S-6 (-298 to +519), and ProT5S-7 $(-154$ to +519$))$ were also subcloned with the same method. Then, the plasmids of ToTLR5M or ToTLR5S were transfected into GPS cells.

Furthermore, the ORF of ToTLR5M and ToTLR5S was cloned into the Nhe I and Kpn I sites of the pCDNA3.1 vector (Invitrogen, USA). The Renilla luciferase plasmid pRL-TK (Promega, WI, USA) was used as an internal control. The TransGen Plasmid Mini Kit (Beijing, China) was used to isolate recombinant plasmids. GPS culture and transfection experiments were performed according to the methods described by Yu et al. (2016) [50]. Additionally, to further investigate the regulatory relationships between two ToTLR5s and ToNF-кB, we also cloned the promoter of ToNF-кB into the Kpn I and Xho I site of the pGL3-basic vector (Invitrogen, USA) (Table 1). Then, ToTLR5M or ToTLR5S or both ToTLR5M and ToTLR5S were transfected into GPS cells together with ToNF-кB. 
Table 1. Primers used for sequence cloning, deletion mutant construction, mRNA construction, and qRT-PCR.

\begin{tabular}{|c|c|}
\hline Subject and Primers & Nucleotide Sequence \\
\hline \multicolumn{2}{|r|}{ Primers for cDNA sequence cloning } \\
\hline TLR5M-F & GCTAGCATGAGGACGCCGGCCCTTCACT \\
\hline TLR5M-R & $\overline{\text { GGTACCTCACATAGCAATTGTTGGGATG }}$ \\
\hline TLR5S-F & GCTAGCATGTGGCTGCTGGGTCTCCAGG \\
\hline TLR5S-R & GGTACCTTACTGCTGTGTGAGCTGAGCA \\
\hline TLR5M-GSP1 & GACACCAAGGTGAAAAAGATTG \\
\hline TLR5M-GSP2 & GACCAAAAGTAGTGTATTCATA \\
\hline TLR5S-GSP1 & ACCAATGTCACCTTCTTGAGTC \\
\hline TLR5S-GSP2 & ACGTATGTCATGTTGATTTGGG \\
\hline \multicolumn{2}{|r|}{ Primers for DNA sequence cloning } \\
\hline TLR5M-F1 & CAACAGCAAAGTTAGATTTACCAAT \\
\hline TLR5M-R1 & CAATTTGAGGTTTAATTGTGTGAAC \\
\hline TLR5M-F2 & AGAGACTCCATACTGACGGAAAGC \\
\hline TLR5M-R2 & AGGAACATGCTATATATCAGCTGT \\
\hline TLR5M-F3 & AAATATGAAGCTACAGCCAGACGC \\
\hline TLR5M-R3 & TGTGAGATTTTGTTTTAATTCTTA \\
\hline TLR5S-F1 & GTTTGTGCTGCACAATCACAGTAATG \\
\hline TLR5S-R1 & CCGTTGTAGGATAGGTCGAGTTTCTG \\
\hline TLR5S-F2 & TCAATTTCCTAAACTTGAACTCTG \\
\hline TLR5S-R2 & GCCCATTTCAGGGGATTTTTTTAT \\
\hline \multicolumn{2}{|r|}{ Deletion mutant construction } \\
\hline Pro-TLR5M-F1 & AAGCTTACCTGCGGTATGGAAGAATGCCCTG \\
\hline Pro-TLR5M-F2 & AAGCTTACCCTCGCACATCACTTCCTTAACC \\
\hline Pro-TLR5M-F3 & AAGCTTACCTAGCTACGGAGGACAGGACTG \\
\hline Pro-TLR5M-F4 & AAGCTTACCAGGTCGGCCGCCCAGAAACC \\
\hline Pro-TLR5M-F5 & AAGCTTACCGACTATGGAAAAGTTACAAG \\
\hline Pro-TLR5M-F6 & AAGCTTACCTACAAGTTAAAGAGCAGAGAG \\
\hline Pro-TLR5M-F7 & AAGCTTACCGAAATGCTCCAGGCGGGTCA \\
\hline Pro-TLR5M-R & GETACCTTAGCTGTCCTCGTCCCACCAAGGCG \\
\hline Pro-TLR5S-F1 & AAGCTTACCGGTCTTTCACTGACTTCCCTAC \\
\hline Pro-TLR5S-F2 & AAGCTTACCTCCAGTGGTGAAAAAGCAGCTG \\
\hline Pro-TLR5S-F3 & AAGCTTACCACCACTCTCTTTAATTATTTACAG \\
\hline Pro-TLR5S-F4 & AAGCTTACCCATTGGGCGCTCAGAAATCACTTG \\
\hline Pro-TLR5S-F5 & AAGCTTACССТССТАСТССТAAAAGTACAATA \\
\hline Pro-TLR5S-F6 & AAGCTTACCGTCTTAATATCTGAAAGAGGAA \\
\hline Pro-TLR5S-F7 & AAGCTTACCGATGCTGTTTTCTGTACTACTGAC \\
\hline Pro-TLR5S-R & 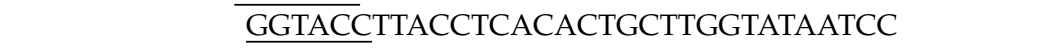 \\
\hline Pro-NF-кB-F & GGTACCGTAAGATCATGTGAACTACC \\
\hline Pro-NF-kB-R & CTCGAGGTATGAAGGTAGTGGTCGTC \\
\hline \multicolumn{2}{|r|}{ Primers for qRT-PCR } \\
\hline qTLR5M-F & TTCAGTCACTCATCTTCCTCAG \\
\hline qTLR5M -R & TCTCGTTCAGCCACTTCAG \\
\hline qTLR5S-F & ТСААССТСТССААСААСТТСА \\
\hline qTLR5S-R & CGGTCATCCAAGCCAGAA \\
\hline $\mathrm{EF} 1 \alpha-\mathrm{F}$ & AAGCCAGGTATGGTTGTCAACTTT \\
\hline $\mathrm{EF} 1 \alpha-\mathrm{R}$ & CGTGGTGCATCTCCACAGACT \\
\hline \multicolumn{2}{|r|}{ Primers for recombinant expression } \\
\hline TLR5M-ED-F & GGATCCGAATTCCGGACTATGCTGGAGCCAAGGGCATTTGC \\
\hline TLR5M-ED-R & GTGGTGCTCGAGTGCGGCCTTATTAATCCTCTTTACATGGTTCGATG \\
\hline TLR5S-ED-F & GGATCCGAATTCCGGACTATGTCATGCCTCATAACGGGCTC \\
\hline TLR5S-ED-R & GTGGTGCTCGAGTGCGGCCTTATTACTGCTGTGTGAGCTGAGCAG \\
\hline \multicolumn{2}{|r|}{ Primers for eukaryotic recombinant vector construction } \\
\hline TLR5M-F & TGGACTAGTGGATCCATGAGGACGCCGGCCCTT \\
\hline TLR5M-R & TTTAAACTTAAGCTTCATAGCAATTGTTGGGAT \\
\hline TLR5S-F & TGGACTAGTGGATCCATGTGGCTGCTGGGTCTC \\
\hline TLR5S-R & TTTAAACTTAAGCTTCTGCTGTGTGAGCTGAGC \\
\hline
\end{tabular}




\subsection{Quantitative Real-time PCR and Statistical Analysis}

The transcription of ToTLR5M and ToTLR5S was determined by quantitative real-time polymerase chain reaction (qRT-PCR) in 10 healthy tissues and 6 infected tissues in pompano. Total RNA was extracted as described previously. The specific primers of two ToTLR5s and the reference gene elongation factor 1 alpha $(E F-1 \alpha)$ are shown in Table 1 . qRT-PCR was performed as previously described [51]. Relative expression was calculated by the $2^{-\Delta \Delta C T}$ method [52]. SPSS 19.0 software (IBM, NC, USA) was used to analyze the data in the present study. The data were analyzed using the Duncan test by one-way ANOVA from different groups and tissues. Data are presented as the means of three replicates \pm standard error (SE), and $p<0.05$ or $p<0.01$ indicated significance.

\subsection{Expression and Purification of Recombinant Two ToTLR5s}

The ToTLR5M functional domain encoding the LRR region and the ORF of ToTLR5S were amplified by PCR with specific primers (Table 1). The corresponding fragments were ligated into the pET-sumo plasmid and transformed into the E. coli Rosseta (DE3) strain. Moreover, positive clones were sequenced and confirmed. To abduct the expression of the recombinant proteins of two ToTLR5s, we supplied isopropyl- $\beta$-D-thiogalactoside (IPTG, $1 \mathrm{mM}$ ) at the 0.6 value that the OD600 of primary culture had attained. Bacterial solution $(1 \mathrm{~mL})$ was collected for analysis after induction at $37^{\circ} \mathrm{C}$ and $220 \mathrm{rpm}$ for $8 \mathrm{~h}$. Furthermore, the control groups were managed analogously without IPTG. According to the His-bind Purification Kit instructions (Novagen), we purified the recombinant proteins of two ToTLR5s and renatured them by Ni-NTA affinity chromatography with chelated nickel ions on the resin. The recombinant proteins were isolated from culture supernatant and separated by sodium dodecyl sulfate polyacrylamide gel electrophoresis (SDS-PAGE; $12 \%$ separating gel and $5 \%$ stacking gel), observed by staining with Coomassie brilliant blue R250, and detected by Western blotting (WT) analysis. A Modified BCA Protein Assay Kit (Sangon Biotech, Shanghai, China) was used to measure the concentration of the ToTLR5M and ToTLR5S proteins.

WT analysis was performed after the purified recombinant ToTLR5M (rToTLR5M) and ToTLR5S (rToTLR5S) was separated by $12 \%$ SDS-PAGE. The outcomes were transferred onto nitrocellulose membrane, washed with PBST (phosphate buffer solution Tween; $0.1 \mathrm{M}$ ) thrice, and blocked with a suspension of $5 \%$ skim milk powder for $2 \mathrm{~h}$. Subsequently, PBST was used to wash the membrane and it was then incubated with His-Tag horseradish peroxidase (HRP) (1:2000) conjugated mouse monoclonal antibody at $37^{\circ} \mathrm{C}$ for $1 \mathrm{~h}$. Enhanced HRP-DAB substrate color development kit was used to develop the immune reactive bands.

\subsection{Assay for the Binding of Bacteria and PAMPs}

To investigate the binding ability of recombinant ToTLR5M (rToTLR5M) and ToTLR5S (rToTLR5S) protein with bacteria and PAMPs, we determined six types of bacteria (Vibrio harveyi, Vibrio vulnificus, Vibrio anguillarum, Staphylococcus aureus, Escherichia coli, Aeromonas hydrophila, Photobacterium damselae) and four types of PAMPs (poly(I:C), LPS, flagellin, and peptidoglycan (PGN); Sigma-Aldrich, USA) by enzyme-linked immunosorbent assay (ELISA). The bacteria were harvested by centrifugation at $12,000 \times g$ for $5 \mathrm{~min}$ after cultivation, washed with PBS three times, and suspended to approximately $1 \times 10^{8} \mathrm{cfu} / \mathrm{mL}$ with PBS. Bacterium and PAMPs were added to each well of a microtiter plate and maintained at $4{ }^{\circ} \mathrm{C}$ for $24 \mathrm{~h}$. The plates were washed three times and then $100 \mu \mathrm{L}$ of various concentrations of recombinant protein or BSA (as a negative control) was added to the wells. Monoclonal His-Tag antibody (1:1000 dilution) was added to each well and incubated at $37^{\circ} \mathrm{C}$ for $1 \mathrm{~h}$. The detailed procedure was described as reported previously [53]. The binding activity of rToTLR5M and rToTLR5S to bacteria or PAMPs was calculated by the OD450 ratio of the treatment and control groups. Positive readings were defined as at least twice that of the control. All assays were implemented in triplicate. 
Supplementary Materials: Supplementary materials can be found at http://www.mdpi.com/1422-0067/21/16/ 5916/s1.

Author Contributions: K.-C.Z., S.-G.J., and D.-C.Z. designed the research and wrote the paper. K.-C.Z. and M.W. performed the research. H.-Y.G. and N.Z. analyzed the data. B.-S.L. and L.G. contributed reagents/materials/analysis tools. All authors have read and agreed to the published version of the manuscript.

Funding: This work was supported by National Key R\&D Program of China (2018YFD0900301); Central Public-Interest Scientific Institution Basal Research Fund, CAFS (NO.2020TD29); China Agriculture Research System (CARS-47); Guangdong Provincial Special Fund for Modern Agriculture Industry Technology Innovation Teams (2019KJ143); Financial Fund of Ministry of Agriculture and Rural Affairs of China (NHYYSWZZZYKZX2020); and Science and Technology Infrastructure Construction Project of Guangdong Province (2019B030316030).

Conflicts of Interest: The authors declare no conflict of interest.

\section{Abbreviations}

$\begin{array}{ll}\text { TLRs } & \text { Toll-like receptors } \\ \text { ORF } & \text { open reading frame } \\ \text { poly(I:C) } & \text { polyinosinic:polycytidylic acid } \\ \text { LPS } & \text { lipopolysaccharide } \\ \text { PAMPs } & \text { pathogen-associated molecular patterns } \\ \text { PGN } & \text { peptidoglycan } \\ \text { PRR } & \text { pathogen recognition receptor } \\ \text { LRRs } & \text { leucine-rich repeats } \\ \text { GPS } & \text { Trachinotus ovatus snout tissue } \\ \text { qRT-PCR } & \text { quantitative real-time polymerase chain reaction } \\ \text { WT } & \text { Western blotting } \\ \text { SDS-PAGE } & \text { sodium dodecyl sulfate polyacrylamide gel electrophoresis } \\ \text { ELISA } & \text { enzyme-linked immunosorbent assay }\end{array}$

\section{References}

1. Purcell, M.K.; Smith, K.D.; Hood, L.; Winton, J.R.; Roach, J.C. Conservation of Toll-like receptor signaling pathways in teleost fish. Comp. Biochem. Physiol. Part D Genom. Proteom. 2006, 1, 77-88.

2. Medzhitov, R. Toll-like receptors and innate immunity. Nat. Rev. Immunol. 2001, 1, 135-145. [CrossRef] [PubMed]

3. Takeda, K.; Kaisho, T.; Akira, S. Toll-like receptors. Annu. Rev. Immunol. 2003, 21, 335-376. [CrossRef] [PubMed]

4. Akira, S.; Takeda, K. Toll-like receptor signalling. Nat. Rev. Immunol. 2004, 4, 499-511. [CrossRef]

5. Janeway, C.A.; Medzhitov, R. Innate immune recognition. Annu. Rev. Immunol. 2002, 20, 197-216. [CrossRef]

6. Akira, S.; Uematsu, S.; Takeuchi, O. Pathogen recognition and innate immunity. Cell 2006, 124, 783-801. [CrossRef]

7. Kawai, T.; Akira, S. The roles of TLRs, RLRs and NLRs in pathogen recognition. Int. Immunol. 2009, 21, 317-337. [CrossRef]

8. Palti, Y. Toll-like receptors in bony fish: From genomics to function. Dev. Comp. Immunol. 2011, 35, 1263-1272. [CrossRef]

9. Means, T.K.; Golenbock, D.T.; Fenton, M.J. Structure and function of Toll-like receptor proteins. Life Sci. 2000, 68, 241-258. [CrossRef]

10. Gewirtz, A.T.; Navas, T.A.; Lyons, S.; Godowski, P.J.; Madara, J.L. Cutting edge: Bacterial flagellin activates basolaterally expressed TLR5 to induce epithelial proinflammatory gene expression. J. Immunol. 2001, 167, 1882-1885. [CrossRef]

11. Hayashi, F.; Smith, K.D.; Ozinsky, A.; Hawn, T.R.; Yi, E.C.; Goodlett, D.R.; Eng, J.K.; Akira, S.; Underhill, D.M.; Aderem, A. The innate immune response to bacterial flagellin is mediated by Toll-like receptor 5. Nature 2001, 410, 1099-1103. [CrossRef] [PubMed]

12. Didierlaurent, A.; Ferrero, I.; Otten, L.A.; Dubois, B.; Reinhardt, M.; Carlsen, H.; Blomhoff, R.; Akira, S.; Kraehenbuhl, J.P.; Sirard, J.C. Flagellin promotes myeloid differentiation factor 88-dependent development of Th2-type response. J. Immunol. 2004, 172, 6922-6930. [CrossRef] [PubMed] 
13. Basu, M.; Swain, B.; Maiti, N.K.; Routray, P.; Samantaa, M. Inductive expression of toll-like receptor 5 (TLR5) and associated downstream signaling molecules following ligand exposure and bacterial infection in the Indian major carp, mrigal (Cirrhinus mrigala). Fish Shellfish Immunol. 2012, 32, 121-131. [CrossRef] [PubMed]

14. Mizel, S.B.; Honko, A.N.; Moors, M.A.; Smith, P.S.; West, A.P. Induction of macrophage nitric oxide production by Gram-negative flagellin involves signaling via heteromeric Toll-like receptor 5/Toll-like receptor 4 complexes. J. Immunol. 2003, 170, 6217-6223. [CrossRef] [PubMed]

15. Oshiumi, H.; Tsujita, T.; Shida, K.; Matsumoto, M.; Ikeo, K.; Seya, T. Prediction of the prototype of the human Toll-like receptor gene family from the pufferfish, Fugu rubripes, genome. Immunogenetics 2003, 54, 791-800. [CrossRef]

16. Tsujita, T.; Tsukada, H.; Nakao, M.; Oshiumi, H.; Matsumoto, M.; Seya, T. Sensing bacterial flagellin by membrane and soluble orthologs of Toll-like receptor 5 in rainbow trout (Onchorhynchus mikiss). J. Biol. Chem. 2004, 279, 48588-48597. [CrossRef]

17. Hwang, S.D.; Asahi, T.; Kondo, H.; Hirono, I.; Aoki, T. Molecular cloning and expression study on Toll-like receptor 5 paralogs in Japanese flounder, Paralichthys olivaceus. Fish Shellfish Immunol. 2010, 29, 630-638. [CrossRef]

18. Bai, J.; Li, Y.; Deng, Y.; Huang, Y.Q.; He, S.H.; Dai, J.; Zhao, S.Z.; Dan, X.M.; Luo, X.C. Molecular identification and expression analysis of TLR5M and TLR5S from orange-spotted grouper (Epinephelus coioides). Fish Shellfish Immunol. 2017, 63, 97-102. [CrossRef]

19. Meijer, A.H.; Gabby, K.S.F.; Medina, R.I.A.; He, S.; Bitter, W.; Ewa, S.J.B.; Spaink, H.P. Expression analysis of the Toll-like receptor and TIR domain adaptor families of zebrafish. Mol. Immunol. 2004, 40, 773-783. [CrossRef]

20. Jiang, Y.; He, L.; Ju, C.; Pei, Y.; Ji, M.; Li, Y.; Liao, L.J.; Jang, S.H.; Zhu, Z.Y.; Wang, Y.P. Isolation and expression of grass carp toll-like receptor $5 \mathrm{a}($ CiTLR5a) and $5 \mathrm{~b}($ CiTLR5b) gene involved in the response to flagellin stimulation and grass carp reovirus infection. Fish Shellfish Immunol. 2015, 44, 88-99. [CrossRef]

21. Umasuthan, N.; Bathige, S.; Thulasitha, W.S.; Jayasooriya, R.G.P.T.; Younhee, S.; Lee, J. Identification of a gene encoding a membrane-anchored toll-like receptor 5 (TLR5M) in Oplegnathus fasciatus that responds to flagellin challenge and activates NF-кB [J]. Fish Shellfish Immunol. 2017, 62, 276-290. [CrossRef] [PubMed]

22. Jayaramu, P.K.; Tripathi, G.; Kumar, A.P.; Keezhedath, J.; Pathan, M.K.; Kurcheti, P.P. Studies on expression pattern of toll-like receptor 5 (TLR5) in Edwardsiella tarda infected Pangasianodon hypophthalmus. Fish Shellfish Immunol. 2017, 63, 68-73. [CrossRef] [PubMed]

23. Morimoto, N.; Kondo, M.; Kono, T.; Sakai, M.; Hikima, J.I. Nonconservation of TLR5 activation site in Edwardsiella tarda flagellin decreases expression of interleukin-1 $\beta$ and NF-kB genes in Japanese flounder, Paralichthys olivaceus. Fish Shellfish Immunol. 2019, 87, 765-771. [CrossRef] [PubMed]

24. Tsoi, S.; Park, K.C.; Kay, H.H.; O’Brien, T.J.; Podor, E.; Sun, G.; Douglas, S.E.; Brown, L.L.; Johnson, S.C. Identification of a transcript encoding a soluble form of toll-like receptor 5 (TLR5) in Atlantic salmon during Aeromonas salmonicida infection. Vet. Immunol. Immunop. 2006, 109, 183-187. [CrossRef]

25. Baoprasertkul, P.; Xu, P.; Peatman, E.; Kucuktas, H.; Liu, Z. Divergent Toll-like receptors in catfish, Ictalurus punctatus: TLR5S, TLR20, TLR21. Fish Shellfish Immunol. 2007, 23, 1218-1230. [CrossRef]

26. Zhang, W.T.; Xiang, J.S.; Li, H.L.; Zhang, N.; Dong, Z.D.; Gao, F.T.; Chen, S.L. Molecular cloning, characterization, and expression of three TLR5S splicing variants in half-smooth tongue sole. J. Fish. Sci. China 2016, 23, 10-20.

27. Huo, R.; Zhao, X.; Han, J.; Xu, T.J. Genomic organization, evolution and functional characterization of soluble toll-like receptor 5 (TLR5S) in miiuy croaker (Miichthys miiuy). Fish Shellfish Immunol. 2018, 80, 109-114. [CrossRef]

28. Sun, L.Y.; Guo, H.Y.; Zhu, C.Y.; Ma, Z.H.; Jiang, S.G.; Zhang, D.C. Genetic polymorphism of breeding populations of golden pompano (Trachinotus ovatus). South China Fish Sci. 2014, 10, 67-71.

29. Zhen, P.L.; Ma, Z.H.; Guo, H.Y.; Jiang, S.G.; Zhang, D.C. Ontogenetic development of caudal skeletons in Trachinotus ovatus larvae, South China. Fish Sci. 2014, 10, 45-50.

30. Su, Y.L.; Feng, J.; Guo, Z.X.; Xu, L.W.; Wang, J.Y. Histopathological analysis of golden pompano Trachinotus ovatus infected with Photobacterium damselae subsp. piscicida. Mar. Sci. 2012, 36, 75-81.

31. Bell, J.K.; Mullen, G.E.; Leifer, C.A.; Mazzoni, A.; Davies, D.R.; Segal, D.M. Leucine-rich repeats and pathogen recognition in Toll-like receptors. Trends Immunol. 2003, 24, 528-533. [CrossRef] 
32. Bell, J.K.; Botos, I.; Hall, P.R.; Askins, J.; Shiloach, J.; Segal, D.M.; Davies, D.R. The molecular structure of the Toll-like receptor 3 ligand-binding domain. Proc. Natl. Acad. Sci. USA 2005, 102, 10976-10980. [CrossRef] [PubMed]

33. Slack, J.L.; Schooley, K.; Bonnert, T.P.; Mitcham, J.L.; Qwarnstrom, E.E.; Sims, J.E.; Dower, S.K. Identification of two major sites in the type I interleukin-1 receptor cytoplasmic region responsible for coupling to pro-inflammatory signaling pathways. J. Biol. Chem. 2000, 275, 4670-4678. [CrossRef]

34. Bilodeau, A.L.; Waldbieser, G.C. Activation of TLR3 and TLR5 in channel catfish exposed to virulent Edwardsiella ictaluri. Dev. Comp. Immunol. 2005, 29, 713-721. [CrossRef]

35. Zhang, X.T.; Zhang, G.R.; Shi, Z.C.; Yuan, Y.J.; Zheng, H.; Lin, L.; Wei, K.J.; Ji, W. Expression analysis of nine Toll-like receptors in yellow catfish (Pelteobagrus fulvidraco) responding to Aeromonas hydrophila challenge. Fish Shellfish Immunol. 2017, 63, 384-393. [CrossRef] [PubMed]

36. Liu, D.; Chen, J.; Li, S.; Hu, G.B. Molecular cloning and expression study on Toll-like receptor 5M in turbot, Scophthalmus maximus. Dev. Comp. Immunol. 2018, 85, 44-50. [CrossRef] [PubMed]

37. Wu, M.; Guo, L.; Zhu, K.C.; Guo, H.Y.; Liu, B.; Jiang, S.G.; Zhang, D.C. Genomic structure and molecular characterization of Toll-like receptors 1 and 2 from golden pompano Trachinotus ovatus (Linnaeus, 1758) and their expression response to three types of pathogen associated molecular patterns. Dev. Comp. Immunol. 2018, 86, 34-40. [CrossRef]

38. Zhu, K.C.; Guo, H.Y.; Zhang, N.; Liu, B.S.; Guo, L.; Jiang, S.G.; Zhang, D.C. Functional characterization of IRF8 regulation of type II IFN in golden pompano (Trachinotus ovatus). Fish Shellfish Immunol. 2019, 94, 1-9. [CrossRef]

39. Zhu, K.C.; Liu, B.S.; Zhang, N.; Guo, H.Y.; Guo, L.; Jiang, S.G.; Zhang, D.C. Interferon regulatory factor 2 plays a positive role in interferon gamma expression in golden pompano, Trachinotus ovatus (Linnaeus 1758). Fish Shellfish Immunol. 2020, 96, 107-113. [CrossRef]

40. Zhu, K.C.; Zhang, N.; Liu, B.S.; Guo, L.; Guo, H.Y.; Jiang, S.G.; Zhang, D.C. Functional analysis of IRF1 reveals its role in the activation of the Type I IFN pathway in golden pompano, Trachinotus ovatus (Linnaeus 1758). Int. J. Mol. Sci. 2020, 21, 2652. [CrossRef]

41. Zhu, K.C.; Guo, H.Y.; Zhang, N.; Guo, L.; Liu, B.S.; Jiang, S.G.; Zhang, D.C. Structural and expression analysis of golden pompano Trachinotus ovatus IRF5 and its role in regulation of type I IFN. Fish Shellfish Immunol. 2020, 97, 313-321. [CrossRef] [PubMed]

42. Zhang, J. Cloning, expression and functional analysis of tlr5/tlr22 and associated downstream signaling molecules in qihe crucian carp (Carassius auratus). Ph.D. Thesis, The Henan Normal University, Xinxiang, China, July 2016.

43. Gao, Q.X.; Yue, Y.F.; Min, M.H.; Peng, S.M.; Shi, Z.H.; Sheng, W.Q.; Zhang, T. Characterization of TLR5 and TLR9 from silver pomfret (Pampus argenteus) and expression profiling in response to bacterial components. Fish Shellfish Immunol. 2018, 80, 241-249. [CrossRef] [PubMed]

44. Thakur, B.K.; Dasgupta, N.; Ta, A.; Das, S. Physiological TLR5 expression in the intestine is regulated by differential DNA binding of Sp1/Sp3 through simultaneous Sp1 dephosphorylation and Sp3 phosphorylation by two different PKC isoforms. Nucleic Acids Res. 2016, 12, 5658-5672. [CrossRef] [PubMed]

45. Moon, J.Y.; Nam, B.H.; Kong, H.J.; Kim, Y.O.; Kim, W.J.; Kim, B.S.; Kim, K.K.; Lee, S.J. Maximal transcriptional activation of piscine soluble Toll-like receptor 5 by the NF-kB subunit 665 and flagellin. Fish Shellfish Immunol. 2011, 6, 881-886. [CrossRef] [PubMed]

46. Huang, W.; Shen, Y.; Xu, X.; Hu, M.Y.; Li, J.L. Identification and characterization of the TLR18 gene in grass carp (Ctenopharyngodon idella). Fish Shellfish Immunol. 2015, 2, 681-688. [CrossRef] [PubMed]

47. Matsumoto, M.; Seya, T. TLR3: Interferon induction by double-stranded RNA including poly (I: C). Adv. Drug Deliver. Rev. 2008, 7, 805-812. [CrossRef]

48. Zhang, D.C.; Guo, L.; Guo, H.Y.; Zhu, K.C.; Li, S.Q.; Zhang, Y.; Zhang, N.; Liu, B.S.; Jiang, S.G.; Li, J.T. Chromosome-level genome assembly of golden pompano (Trachinotus ovatus) in the family Carangidae. Sci. Data 2019, 6, 216. [CrossRef]

49. Sun, L.Y.; Zhang, D.C.; Jiang, S.G.; Guo, H.Y.; Zhu, C.Y. Isolation and characterization of 21 polymorphic microstatellites in golden pompano Trachinotus ovatus. Conserv. Genet. Resour. 2013, 5, 1107-1109. [CrossRef]

50. Yu, Y.; Wei, S.; Wang, Z.; Huang, X.; Huang, Y.; Cai, J.; Li, C.; Qin, Q. Establishment of a new cell line from the snout tissue of golden pompano Trachinotus ovatus, and its application in virus susceptibility. Fish Biol. 2016, 88, 2251-2262. [CrossRef] 
51. Zhu, K.C.; Song, L.; Guo, H.Y.; Guo, L.; Zhang, N.; Liu, B.S.; Jiang, S.G.; Zhang, D.C. Elovl4a participates in LC-PUFA biosynthesis and is regulated by PPAR $\alpha \beta$ in golden pompano Trachinotus ovatus (Linnaeus 1758). Sci. Rep. 2019, 9, 4684. [CrossRef]

52. Livak, K.J.; Schmittgen, T.D. Analysis of relative gene expression data using realtime quantitative PCR and the $2^{-\Delta \Delta C T}$ method. Methods 2001, 25, 402-408. [CrossRef] [PubMed]

53. Wang, T.; Sun, L. CsSAP, a teleost serum amyloid P component, interacts with bacteria, promotes phagocytosis, and enhances host resistance against bacterial and viral infection. Dev. Comp. Immunol. 2016, 55, 12-20. [CrossRef] [PubMed]

(C) 2020 by the authors. Licensee MDPI, Basel, Switzerland. This article is an open access article distributed under the terms and conditions of the Creative Commons Attribution (CC BY) license (http://creativecommons.org/licenses/by/4.0/). 